\title{
Trajetórias de uma estudante Iny(Karajá): narrativa de acesso e permanência no curso superior
}

\author{
Vanessa Hãtxu de Moura Karajá1
}

DOI: http://dx.doi.org/10.20435/tellus.v20i41.638

Pertenço ao povo indígena Iny, "nós" é a forma com que nos autodenominamos. Mas somos mais conhecidos como Karajá. Segundo a cosmologia, o povo Iny viemos do Berahatxi Mahãdu, o povo do fundo das águas do Rio Araguaia; vivemos às margens dele, que se localiza nos estados de Goiás, Mato Grosso, Pará e Tocantins. Falamos a língua Iny rèbe, pertencente ao tronco linguístico Macro-Jê. Atualmente, nas comunidades Iny, há um grande número de jovens, e eu particularmente pertenço à Aldeia Lago Grande (não demarcada), em que a cidade mais próxima é o município de Santa Terezinha, MT. Muitos jovens Iny estão buscando se fortalecer e estão em busca de melhorias para suas comunidades. Ingressar nas universidades é um instrumento de luta e, ao mesmo tempo, de resistência!

E sigo compondo a resistência com o meu povo. No ano de 2014, decidi fazer o vestibular e consegui ser aprovada; foi a primeira vez que consegui ingressar em uma universidade, na Universidade Federal do Tocantins, no curso de Ciências Contábeis. Deixei com meus pais meu filho David Vinnycius Mahalani De Moura Karajá, com dois anos de idade, estudei um semestre, mas acabei desistindo do curso. Não me identifiquei com o curso e sentia muitas dificuldades nas disciplinas, não conseguia compreender quase nada, as disciplinas nas áreas de exatas são complexas e nós estudantes indígenas às vezes passamos por muita dificuldade.

Logo depois, em 2015, consegui ingressar novamente na universidade, mas desta vez na Universidade Federal de Goiás. Estudei dois semestres, mas engravidei nesse período; eu, que já tinha mais um filho, estava grávida de novo. Quando estava próximo de minha filha nascer, tranquei a faculdade e fui para aldeia, pois morava na Casa do Estudante da universidade e não era permitido estudantes

\footnotetext{
${ }^{1}$ Universidade Federal de Goiás (UFG), Goiânia, Goiás, Brasil.
} 
morarem com crianças na casa. Para nós, ter filhos é sinal de vida e muita alegria, muito diferente na concepção não indígena, já que pensam nos gastos financeiros, veem as crianças como atraso/problemas para seus pais.

Foi aí que eu pude perceber que viver na sociedade não indígena e estudar na universidade não é para qualquer um, e que estudantes mães/indígenas não se encaixam nesse sistema egoísta. Fui para a aldeia do meu companheiro, Leomar Wainnê Xerente, que também é estudante desta universidade (UFG). Fiquei um tempo na aldeia e já estava desistindo de continuar o curso, mas sou resistente; voltei para a universidade, mas deixei minha filha de apenas um ano na aldeia Mrâiwahã, TO.

Não foi fácil, eu estava amamentando a minha filha, Thayná Waiti Kuahiru Xerente. Quantas vezes chorei e ainda choro! Ser estudante, mãe e indígena não é nada fácil, mas somos persistentes, não sou a primeira nem a última estudante indígena a passar por isso. Esse é um dos desafios das Mulheres e Mães Indígenas, principalmente das mais pobres. Sou estudante indígena, assim como muitas(os) como eu, que sonham se formar em um curso superior, mas que se sacrificam de alguma forma com intuito de futuramente poder retribuir de alguma forma com sua comunidade.

Acredito que para nós, como estudantes/mães indígenas, este acesso à educação superior também é romper paradigmas. Quantas conseguem este acesso? "Ter filhos não é um obstáculo para a continuidade de seus estudos, muito pelo contrário, pois elas sentem orgulho em mostrar a eles o quanto é importante se qualificar e, dessa forma, lutar pelos seus direitos" (BERGAMASCHI; KURROSCHI, 2013).

A nossa permanência nesse espaço possui grandes desafios. Nossa decisão de sair da comunidade é algo difícil, pois nós indígenas somos muito ligados aos laços familiares e a palavra COMUNIDADE carrega significados fundamentais para as nossas vidas. Estamos ocupando a linha de frente nessa luta por uma educação de qualidade, acreditamos que, com nossa presença, surgirão, sim, transformações e mudanças para melhor.

Estou quase me formando no curso de Pedagogia, em breve voltarei para minha comunidade e quero retribuir com o trabalho e lutar por nossos direitos. Pois nós estudantes indígenas, depois de formados, nosso objetivo é retornar para nossas comunidades, para que juntos possamos lutar em busca de melhorias. 
Afinal de contas, os indígenas formados nas universidades acumularam conhecimentos novos, que os capacitaram a uma visão crítica e transformadora, e ao retornarem para suas comunidades estarão sedentos de contribuir para as mudanças que precisam ser feitas pela comunidade para melhorar as condições de vidas das pessoas. (BANIWA; HOFFMANN; OLIVEIRA, 2010, p. 9)

Durante séculos, fomos excluídos da universidade. Por muito tempo, fomos e infelizmente somos até hoje vistos como incapazes, mas agora nas universidades estamos mostrando competência. Conforme Claudino (2013 apud BERGAMASCHI; KURROSCHI, 2013): "Agora, na universidade, deixamos de ser objeto, para ser sujeito da pesquisa". Que nós não sejamos vistos como pessoas incapazes, queremos que a universidade seja espaço de diálogos e troca de conhecimentos, que ocorra uma verdadeira inclusão. Não queremos ser objeto de estudo! Desejamos compartilhar nossos saberes, nossa forma de bem viver, a nossa presença no espaço acadêmico nos faz refletir e querer inovar, criar novas formas de ver o mundo.

Os povos indígenas gostariam de compartilhar com o mundo, a partir da universidade, seus saberes, seus valores comunitários, suas cosmologias, suas visões de mundo e seus modos de ser, de viver e de estar no mundo, onde o bem viver coletivo é a prioridade. (BANIWA, 2014)

Nos últimos anos, avanços nas políticas públicas voltados ao Ensino Superior foram de extrema relevância para que fosse, sim, possível a presença de indígenas nas universidades. Vale ressaltar a importância da lei de cotas aprovadas em 2012. "Esta Lei estabelece a obrigatoriedade da reserva de vagas nas Universidades e Institutos Federais, combinando frequência à escola pública com renda e cor (etnia)" (BANIWA, 2014). Questões sobre ingresso e permanência são fundamentais para que nós indígenas consigamos acessar o Ensino Superior, já que durante muitos séculos fomos excluídos desse espaço.

[...] questões centrais: ingresso de estudantes indígenas (modelos de implantação da política e processos seletivos para ingresso) e questões relacionadas à permanência desses estudantes (programas de apoio financeiro e pedagógico, relação institucional com os estudantes, ações de acompanhamento e desafios institucionais na garantia da permanência). (BERGAMASCHI; DOEBBER; BRITO, 2018)

O Ministério da Educação (MEC) instituiu em 2013 o Programa Bolsa Permanência (BRASIL, 2013), que possibilitou um aumento significativo de estu- 
dantes indígenas e quilombolas nas universidades no país. Mas para a permanência de estudantes indígenas não basta só a Bolsa Permanência, a "permanência também se estabelece na medida em que se constituem relações de afetividade no processo de inserção no mundo acadêmico" (BERGAMASCHI; DOEBBER; BRITO, 2018). Para permanência de estudantes indígenas nas universidades, auxílios financeiros não são o suficiente, e sim um conjunto de fatores que incluem uma aceitação e afetividade.

Por que me leva a escrever uma narrativa? Quantas narrativas indígenas ouvimos? Refletindo sobre isso, resolvi assim escrever, escrever o que sinto, o que penso. Anzaduá, em uma carta, relata a importância de escrever:

Por que sou levada a escrever? Porque a escrita me salva da complacência que me amedronta. Porque não tenho escolha. Porque devo manter vivo o espírito de minha revolta em mim mesma também. Porque o mundo que crio na escrita compensa o que o mundo real não me dá. No escrever coloco ordem no mundo, coloco nele uma alça para poder segurá-lo. Escrevo porque a vida não aplaca meus apetites e minha fome. Escrevo para registrar o que os outros apagam quando falo, para reescrever as histórias mal escritas sobre mim, sobre você. (ANZALDÚA, 2000, p. 232)

A escrita para nós é um grande desafio, pois somos de cultura da oralidade, mas temos sentido que escrever também faz parte das nossas lutas e das nossas conquistas. Escrevemos para que outras mulheres indígenas também possam se sentir estimuladas a ocupar esses espaços, para que também vejam como possibilidade de ser autoras de suas histórias em seus diferentes percursos. Concluo o trabalho com as seguintes indagações: o que é necessário para transformar o Currículo? Será que as políticas adotadas para a inclusão de estudantes indígenas estão sendo suficientes para permanência na universidade?

\section{REFERÊNCIAS}

ANZALDÚA, G. Falando em línguas: uma carta para as mulheres escritoras do terceiro mundo. Revista Estudos Feministas, Florianópolis, v. 8, n. 1, p. 229-36, 1o sem. 2000.

BANIWA, G. A Lei das Cotas e os povos indígenas: mais um desafio para a diversidade. Cadernos de Pensamento Crítico Latino-Americano, n. 34, 2014. Disponível em: http:// flacso.org.br/files/2014/12/XXXVcadernopensamentocritico.pdf 
BANIWA, G. J. S.; HOFFMANN, M. B.; OLIVEIRA, J. C. Olhares indígenas contemporâneos. Brasília: Centro Indígena de Estudos e Pesquisas, 2010.

BERGAMASCHI, M. A.; DOEBBER, M. B.; BRITO, P. O. Estudantes indígenas em universidades brasileiras: um estudo das políticas de acesso e permanência. Revista Brasileira de Estudos Pedagógicos, Brasília, v. 99, n. 251, p. 37-53, jan./abr. 2018. http://dx.doi. org/10.24109/2176-6681.rbep.99i251.3337

BERGAMASCHI, M. A.; KURROSCHI, A. R. S. Estudantes indígenas no ensino superior: o programa de acesso e permanência na UFRGS. Políticas Educativas, Porto Alegre, v. 6, n. 2, p. 1-20, 2013. Disponível em: https://www.seer.ufrgs.br/Poled/article/ viewFile/45654/28834. Acesso em: 11 nov. 2018.

BRASIL. Ministério da Educação (MEC). Portaria n. 389, de 9 de maio de 2013. Cria o Programa de Bolsa Permanência e dá outras providências. Diário Oficial da União, Brasília, Seção 1, p. 12, 13 maio 2013.

\section{Sobre a autora:}

Vanessa Hãtxu de Moura Karajá: Estudante indígena do povo iny(Karajá), cursa Pedagogia na Universidade Federal de Goiás. E-mail: vns.hatxu@gmail.com, Orcid: https://orcid.org/0000-0001-8304-2406.

Recebido em 3 de julho de 2019.

Aprovado para publicação em 16 de setembro de 2019. 
